\title{
Skin Irritation
}

National Cancer Institute

\section{Source}

National Cancer Institute. Skin Irritation. NCI Thesaurus. Code C50743.

A mild inflammatory dermal tissue reaction; it can be caused by physical contact with an irritant or can be a local response to a systemic trigger. 